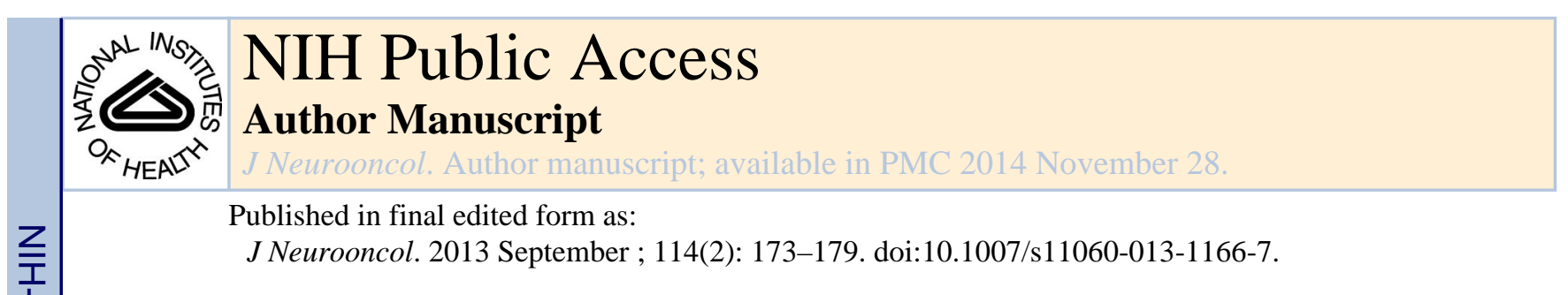

\title{
A MOLECULAR BIOLOGY AND PHASE II TRIAL OF LAPATINIB IN CHILDREN WITH REFRACTORY CNS MALIGNANCIES: A PEDIATRIC BRAIN TUMOR CONSORTIUM STUDY
}

\author{
Maryam Fouladi, Clinton F. Stewart, Susan M. Blaney, Arzu Onar-Thomas, Paula \\ Schaiquevich, Roger J. Packer, Stewart Goldman, J. Russell Geyer, Amar Gajjar, Larry E. \\ Kun, James M. Boyett, and Richard J. Gilbertson \\ St Jude Children's Research Hospital, Memphis, TN (M.F.; C.F.S., A.O., P.S., A.G., L.E.K., \\ J.M.B., R.J.G); Texas Children's Cancer Center/Baylor College of Medicine, Houston, TX \\ (S.M.B.); Children's National Medical Center, Washington, DC (R.J.P.) Anne and Robert H. Lurie \\ Children's Hospital of Chicago, Chicago, IL (S.G.), Children's Hospital and Regional Medical \\ Center, Seattle, WA.(R.G)
}

\begin{abstract}
Background-High expression of ERBB2 has been reported in medulloblastoma and ependymoma; EGFR is amplified and over-expressed in brainstem glioma suggesting these proteins as potential therapeutic targets. We conducted a molecular biology (MB) and phase II study to estimate inhibition of tumor ERBB signaling and sustained responses by lapatinib in children with recurrent CNS malignancies.
\end{abstract}

Patients and Methods-In the MB study, patients with recurrent medulloblastoma, ependymoma, and high-grade glioma (HGG) undergoing resection were stratified and randomized to pre-resection treatment with lapatinib $900 \mathrm{mg} / \mathrm{m}^{2} /$ dose bid for $7-14$ days or no treatment. Western blot analysis of ERBB expression and pathway activity in fresh tumor obtained at surgery estimated ERBB receptor signaling inhibition in vivo. Drug concentration was simultaneously assessed in tumor and plasma. In the phase II study, patients, stratified by histology, received lapatinib continuously, to assess sustained response.

Results-Eight patients, on the MB trial (4 medulloblastomas, 4 ependymomas), received a median of 2 courses (range: 1-6+). No intratumoral target inhibition by lapatinib was noted in any patient. Tumor-to-plasma ratios of lapatinib were 10-20\%. In the 34 patients (14 MB, 10 HGG, 10 ependymoma) in the phase II study, lapatinib was well-tolerated at $900 \mathrm{mg} / \mathrm{m}^{2} / \mathrm{dose}$ bid. The median number of courses in the phase II trial was 2 (range 1-12). Seven patients (3 medulloblastoma, 4 ependymoma) remained on therapy for at least 4 courses range (4-26).

Conclusion-Lapatinib was well-tolerated in children with recurrent or CNS malignancies, but did not inhibit target in tumor and had little single agent activity.

Corresponding author: Maryam Fouladi, M.D., Cancer and Blood Disorders Institute, Cincinnati Children's Hospital Medical Center, 3333 Burnet Avenue, Cincinnati, OH, 45229, Telephone: (513) 803-0721, Telefax: (513) 636-3549, maryam.fouladi@ cchmc.org.

None of the authors reported any conflicts of interest. 


\section{Keywords}

Lapatinib; medulloblastoma; high-grade glioma; phase II trial

\section{INTRODUCTION}

A comprehensive study of molecular targeted therapeutics should include an assessment of target inhibition in vivo [1,2]. While this is relatively straightforward in preclinical model systems, measuring drug-target inhibition in children with recurrent deep-seated pediatric brain tumors is more difficult; particularly in early clinical trials when re-resection is generally not performed. Although we routinely measure in vivo drug activity in more accessible, surrogate tissues (e.g. peripheral blood mononuclear cells [3,4]), these tissues may not express the appropriate target protein, and their pattern of drug-target inhibition might not correlate with that in tumor. Thus, direct simultaneous measurement of drug concentration and target inhibition in tumors provides unprecedented data to correlate with measures of drug pharmacokinetics and clinical response [5,1,2].

Recently, we reported the results of a phase I study of the Epidermal Growth Factor Receptor (EGFR) and ERBB2 tyrosine kinase inhibitor, lapatinib, in children with recurrent brain tumors [6]. High expression of ERBB2 has been reported in medulloblastoma [7,8] and ependymoma [9]; EGFR is amplified and over-expressed in brainstem glioma [10] suggesting these proteins as potential therapeutic targets. The combination of lapatinib and capecitabine has proven active in first line treatment of brain metastases from ERBB-2 positive breast cancer [11]. Lapatinib is FDA approved for treatment of postmenopausal women with hormone receptor positive metastatatic breast cancer that overexpresses ERBB2.

To better understand efficacy and EGFR/ERB2 signaling blockade of lapatinib in brain tumors, we conducted a molecular biology and phase II study in children. Children with local recurrence of medulloblastoma/primitive neuroectodermal tumor (PNET), ependymoma or high-grade glioma (HGG) for whom surgical resection was planned were randomized to receive lapatinib or no drug for 7-10 days prior to surgery. Tumors were removed and levels of intratumoral EGFR/ERBB2 receptor activity and drug concentration were measured. Patients with post-operative residual recurrent medulloblastoma/PNET, HGG or ependymoma were also included in Phase II estimates of sustained response rates to lapatinib.

\section{PATIENTS AND METHODS}

\section{Patient Eligibility}

Common eligibility criteria for both the molecular biology and phase II study included patients aged $\leq 21$ years with a histological verified medulloblastoma/PNET, ependymoma and HGG (anaplastic astrocytoma, glioblastoma multiforme, gliosarcoma, anaplastic oligodendroglioma) refractory to conventional therapy. Other eligibility criteria were similar to those employed in our phase I trial [3]. For the molecular biology study, patients needed 
to have tumors for which surgical resection was clinically indicated and were amenable to receiving lapatinib for 7-14 days prior to resection. For the phase II study, patients had to have measureable disease. Informed consent was obtained from patients, parents or guardians, and assent was obtained as appropriate at the time of protocol enrollment. The institutional review boards of each PBTC institution approved the protocol before patient enrollment and continuing approval was maintained throughout the study.

\section{Drug Administration}

Lapatinib, supplied by the Cancer Therapy Evaluation Program (NCI, Bethesda, MD) as a $250 \mathrm{mg}$ oval, film-coated tablet, was administered orally, twice daily. Each course was 28 days in length. Tablets could be cut in half; total daily doses were rounded to the nearest 125 mg. For patients with difficulty swallowing, lapatinib tablets were added to 2-4 oz of water or Kool-Aid or $3 \mathrm{oz}$ of chocolate milk and stirred to form a suspension. A dosing nomogram based on body surface area and dosage level (rounded to the nearest $125 \mathrm{mg}$ ) was used to minimize interpatient dosing variability. The lapatinib dosage was $900 \mathrm{mg} / \mathrm{m}^{2} / \mathrm{dose}$ twice daily, the MTD established in the recently published phase I study. Patients could receive up to 26 courses in the absence of disease progression.

\section{Dose Modifications}

Hematologic dose modifying toxicity was defined as grade 4 neutropenia or grade 3 or 4 thrombocytopenia related to lapatinib. Non-hematologic dose modifying toxicity was defined as any grade 3 or 4 non-hematological toxicity with the specific exclusion of: grade 3 nausea and vomiting controlled with adequate antiemetics; grade 3 fever or infection; grade 3 diarrhea responsive to optimal use of loperamide; grade 3 or 4 hypokalemia, hypophosphatemia or hypomagnesemia which resolve to sgrade 2 by supplementation within 7 days. Any grade 2 non-hematological toxicity that persisted for $>7$ days and was considered sufficiently intolerable by patients as to warrant treatment interruption and/or dose reduction was considered dose-limiting.

\section{Pretreatment Evaluations and Evaluations During Therapy}

Pretreatment evaluations included a history, physical examination, performance status, disease evaluation, complete blood count (CBC), electrolytes, renal and liver function tests, pregnancy test for female patients of childbearing age, echocardiogram/gated radionuclide study (MUGA). CBCs were obtained every 2 weeks during course 1 and prior to each subsequent course. History, physical examinations, and serum chemistries were obtained every 2 weeks in course 1 and prior to each subsequent course. Echocardiogram/MUGA was obtained at the end of course 2 and every 12 weeks thereafter.

\section{Response Criteria}

Disease evaluations were obtained at baseline, after course 2 and every other course, thereafter. Tumor response was defined as follows: complete response (CR), disappearance of all measurable lesions on magnetic resonance imaging (MRI); partial response (PR), $\geq 50 \%$ reduction in tumor size by bidimensional measurement on a stable or decreasing dose of corticosteroids, accompanied by a stable or improving neurological exam and maintained 
for at least 8 weeks; progressive disease (PD), worsening neurologic status or $>25 \%$ increase in the bidimensional measurement, or appearance of new lesions, or increasing corticosteroids doses; stable disease (SD), MRI response does not meet the criteria for other categories, with stable neurologic examination and corticosteroid dose.

\section{Pharmacokinetic Studies}

Pharmacokinetic studies were performed in all consenting patients on the molecular biology and Phase II studies. In the molecular biology study, patients had a plasma sample and a sample of tumor tissue obtained during surgery. Tumor tissue harvested during surgery was weighed, diluted in an appropriate volume of buffer, and mechanically homogenized. Lapatinib concentrations were determined by a liquid chromatography electrospray tandem mass spectrometry (LC-ESI-MS/MS) method, with a lower limit of quantitation of $1 \mathrm{ng} / \mathrm{ml}$ in plasma and $10 \mathrm{ng} / \mathrm{ml}$ in brain tumor tissue extracts [12]. In the Phase II study plasma samples were obtained with the first dose of Courses 1 and 2. Serial whole blood samples (2 $\mathrm{ml}$ ) were collected in heparinized tubes before the dose, and $0.5,1,1.5,3,6$, and 8 hours after administration. ${ }^{12}$ Pharmacokinetic parameters for lapatinib were calculated using noncompartmental methods. For each patient, the maximum concentration $\left(\mathrm{C}_{\max }\right)$ and time to maximum concentration $\left(\mathrm{t}_{\max }\right)$ were the observed values. The area under the plasma concentration-time curve $\left(\mathrm{AUC}_{0 \rightarrow \mathrm{t}}\right.$ where $\mathrm{t}$ was the last measured time point) was calculated by the trapezoidal rule.

\section{ERBB Receptor Expression and Signal Activity}

Expression and activation of the ERBB signaling network was analyzed in tumor samples using previously described immunohistochemical (IHC) techniques [7,9]. Fixed tumor material was also used for central histopathology review to confirm diagnosis. To determine lapatinib's ability to inhibit tumor ERBB receptor signaling, we compared pathway activity in tumors from patients who received drug, with those who did not. Fresh frozen tumor material was harvested at surgery following 7-14 days of lapatinib or placebo or from pretrial tumor samples, and subjected to quantitative western blot analysis of phosphoEGFR and phospho-ERBB2, normalized to the level of total receptor protein and total (housekeeping protein) in each sample. As another measure of baseline ERBB signaling activity in tumor samples, we also analyzed an additional cohort of ependymomas $(n=14)$ collected as part of the Phase I and II components of this study. These data were correlated with parallel pharmacokinetic measures of tumor drug concentrations and patient progression free survival (PFS).

\section{Statistical Considerations}

The primary objective of the study was to determine the true sustained objective response (CR and PR) rate to lapatinib in children with recurrent or refractory medulloblastoma/ PNET (Stratum A), HGG (Stratum B) and ependymoma (Stratum C). The response evaluation period was set as 4 courses for Strata A and B and as 6 courses for Stratum C. Only responses sustained for at least 8 weeks were counted towards the primary endpoint. Patients who received $<50 \%$ of the expected total dose or patients who withdrew from treatment during the first 2 courses for reasons other than progressive disease or death were considered inevaluable for response and were replaced. Simon's Minimax Two Stage 
Design was used separately for each stratum with $a=10 \%$ and $90 \%$ power. For Stratum A, response rates of $15 \%$ (unacceptable) vs. $35 \%$ (desirable) were used which lead to a first stage sample size of 17 and a total sample size of 32. At the interim analysis 3 or more responses were needed to expand the sample size to 32 where 8 or more responses would lead to declaring the trial a success. Though applied separately, the design for Strata B and C were identical with response rates of 5\% (unacceptable) vs. $25 \%$ (desirable). This led to a sample size of 13 at the interim analysis and an overall sample size of 20. One response was adequate to expand the cohort beyond the interim analysis and 3 or more responses were needed to declare the trial a success in these two strata. Ten patients (3 in Stratum A, 3 in Stratum B and 4 in Stratum C) who were treated at the MTD during the Phase I trial and who met the eligibility criteria for the Phase II trial were counted towards the accrual of the Phase II trial. All summary statistics and tables provided here include these patients.

The molecular biology trial was designed to detect 5\% vs. 60\% inhibition of ERBB receptor signaling in the patients who were randomized to not receive vs. to receive lapatinib for 714 days prior to surgery, respectively. The molecular biologist who determined the level of receptor phosphorylation was masked to the treatment groups. While the randomization was stratified, there was no a priori reason to expect that the agent's ability to inhibit ERBB signaling would differ across histologies. Hence the design was based on an overall comparison of ERBB signaling between the two randomized groups. The sample size calculation utilized a binomial distribution with $a=5 \%$ and $90 \%$ power resulting in a sample size of 28 patients whose tumors expressed ERBB. Based on previously published information $[13,14]$ it was estimated that up to 45 patients would have to be randomized to accrue 28 patients whose tumors expressed ERBB. While the two trials were designed separately, the accrual to the Molecular Biology trial was contingent upon accrual being open for the Phase II trial. Hence when accrual to a stratum of the phase II trial was suspended or closed, accrual to the corresponding stratum of the Molecular Biology trial was also suspended or closed.

\section{RESULTS}

\section{Patient Characteristics}

Eight patients, 4 with ependymoma and 4 with medulloblastoma were enrolled on the molecular biology study; one medulloblastoma patient was not evaluable for the molecular biology objective as no fresh frozen tissue was submitted. Forty-four patients, all eligible, were enrolled on the phase II study; 17 on stratum A (medulloblastoma), 13 on stratum B (HGG) and 14 on stratum C (ependymoma). Three were inevaluable for response because of progression prior to treatment $(\mathrm{n}=1)$ or withdrawal from treatment during the first course of therapy ( $\mathrm{n}=2)$. Table 1 and 2 summarize the characteristics of the eligible patients in the molecular biology and phase II studies, respectively. The median number of courses in all strata was 2 (range, 1-26). The accrual to the phase II trial was 2.5 to 3 times faster than anticipated and accrual to the molecular biology trial was on target. However, all 3 strata were closed for lack of efficacy following planned interim analyses, thus limiting enrollment to the molecular biology study. No pre-, intra, or post-operative complications were observed among patients treated within the molecular biology study. 


\section{ERBB Receptor Inhibition in the Molecular Biology Study}

Of seven evaluable patients on the molecular biology study, four with ependymoma and three with medulloblatoma were randomized to receive lapatinib or no-treatment, respectively, prior to surgery. No significant difference was observed in the relative phosphorylation (RPS) of the EGFR receptor in tumors exposed to lapatinib (median RPS $=0.94$, range 0.16-3.07) relative to no treatment (median RPS $=0.82$, range 0.68-3.24) by western blotting. The RPS of ERBB2 in lapatinib treated tumors (median $=0.21$, range $0.03-0.44$ ) was less than half of that observed in untreated tumors (median $=0.50$, range 0.05-1.66), although the numbers were insufficient for adequate assessment of statistical significance. A broad range of EGFR and ERBB2 RPS was observed in the 14 control patients and was not significantly different from either placebo or control treated patients.

Formalin fixed paraffin embedded (FFPE) tumor material was available for 25 patients ( 9 , medulloblastoma; 7 glioma; 9 ependymoma) in the Phase II trial. As reported previously total $(\mathrm{P}=0.04)$ and phospho-ERBB2 levels were highest in ependymomas [6]. No significant relationship was observed between time to progression and IHC determined expression and phosphorylation of EGFR, ERBB2, ERK or pS6 in any stratum.

\section{Pharmacokinetics}

Three and 16 patients consented to pharmacokinetic studies on the molecular biology and phase II studies, respectively. In the three patients for whom perioperative tumor and plasma samples were obtained, the median (range) plasma and tumor lapatinib values were 2170 $\mathrm{ng} / \mathrm{ml}(973$ to $5330 \mathrm{ng} / \mathrm{ml}$ ) and $472 \mathrm{ng} / \mathrm{g}$ (173 to $599 \mathrm{ng} / \mathrm{g}$ ), respectively. Although they varied widely, lapatinib brain tumor penetration reached 10 to $20 \%$ of the observed plasma concentration $(0.18,0.11$, and 0.22$)$.

Of the 16 phase II patients studied, 5 had repeat studies during the second course. In 13 patients during course 1, the median (range) lapatinib maximum plasma concentration and time of maximum plasma concentration were $5050 \mathrm{ng} / \mathrm{ml}(1915$ to $10500 \mathrm{ng} / \mathrm{ml})$ and $3.2 \mathrm{hr}$ (1.5 to $8.9 \mathrm{hr}$ ), respectively. In five patients studied at steady-state (after course 1), the median (range) lapatinib maximum plasma concentration and time of maximum plasma concentration were $5080 \mathrm{ng} / \mathrm{ml}$ ( 2530 to $10300 \mathrm{ng} / \mathrm{ml})$ and $3.0 \mathrm{hr}(1.5$ to $8.1 \mathrm{hr}$ ), respectively. No apparent effect of dexamethasone upon lapatinib systemic exposure was noted in this small number of patients.

\section{Toxicity}

All patients who received at least 1 dose of lapatinib were evaluable for assessing toxicity. Tables 3 and 4 summarize the number of adverse events that were $\geq$ Grade 2, attributed to therapy and observed in $>10 \%$ of evaluable patients in at least 1 stratum for the molecular biology and phase II studies, respectively. Lapatinib was well-tolerated. The most common grade 3 and 4 adverse events in the molecular biology and phase II studies included diarrhea (7 episodes in 7 patients), hypokalemia (7 episodes in 6 patients) and lymphopenia (4 episodes in 4 patients). 


\section{Responses}

No objective responses (OR) were reported. Prolonged SD ( $\geq 4$ courses of therapy) was observed in 3 patients (4, 6 and 26 courses, respectively) in stratum A (medulloblastoma/ PNET) and 4 patients in stratum C (ependymoma) $(4,12,21$ and 26 courses, respectively) in the phase II study.

\section{DISCUSSION}

This study demonstrates that lapatinib was well-tolerated, but had little activity in children with recurrent CNS malignancies. No objective responses were observed and only 7 of 44 phase II patients had SD for $\geq 4$ courses. Similar to adult studies, the most common side effects included diarrhea and rash.

The plasma lapatinib PK profile was similar to that measured in our phase I study [6], but, to our knowledge, this is the first published report of intratumoral lapatinib concentrations in children with recurrent CNS malignancies. The range and time of maximum plasma concentration values overlapped with those published from the phase I study at the MTD. We reported an effect of dexamethasone in our phase I study, but in this small cohort of patients we did not observe a similar effect [6]. The lapatinib plasma concentration values identified in our study were similar to those reported by Guo and colleagues in their studies of adult glioblastoma ( 900 to $5000 \mathrm{ng} / \mathrm{ml}$ in the two studies); however, we observed much lower lapatinib levels in tumor ( 10 to $20 \%$ of simultaneous plasma sample) [15]: Intratumoral concentrations reported by Guo and colleagues ranged from 3500 to 12,600 $\mathrm{ng} / \mathrm{ml}$ compared with 970 to $5330 \mathrm{ng} / \mathrm{ml}$ in our study. Results from a more recent study of lapatinib CNS distribution in mice harboring MDA-MD-231-BR-HER2 xenografts also reported low lapatinib penetration in CNS metastases (e.g., $~ 1.3$ to $2.8 \%$ of matching plasma concentrations) [16]. Further studies will be required to determine if differences in bloodtumor barriers among various cancers account for these observed differences in drug penetration.

Unique to our study was measurement of target inhibition in brain tumors resected from lapatinib treated children. No significant difference in the RPS of the EGF or ERBB2 receptors was observed in tumors exposed to lapatinib compared to untreated tumor. These data are compatible with the low intratumoral concentrations of lapatinib measured in tumors. Intratumoral concentrations in our patients ranged from 183 to $634 \mathrm{nM}$; significantly less than concentrations required to inhibit ERBB2 in isolated cells, including those overexpressing ERBB2 [17]. Although these concentrations are above the $\mathrm{Kd}$ for binding of lapatinib to free EGFR and ERBB2 protein ( 3 and 13, nM respectively), ${ }^{16}$ lapatinib is highly protein-bound, therefore actual free lapatinib levels in the brain tumors in our studies are likely to be closer to $1-6 \mathrm{nM}$ (1\% of total) [16]. Thus, we conclude that lapatinib penetrates pediatric brain tumors at concentrations below that required to inhibit the ERBB receptors. This poor penetration may explain the observed lack of molecular and clinical activity in our study. Recent data in adults with NF2 and vestibular schwanommas, have shown that, despite biologically relevant concentrations of lapatinib in tumor tissue (15.52 micromolar), tumor levels of EGFR, ERB2, ERK, and AKT phosphorylation were similar between 
patients treated with lapatinib and placebo implying that much higher levels of lapatinib may be required to inhibit ERBB receptors in vivo compared to cells in vitro [18].

In summary, lapatinib's lack of intratumoral target inhibition and efficacy in children with recurrent CNS tumors may be explained by the fact that intratumoral lapatinib concentrations were well below the $\mathrm{IC}_{50}$ required to inhibit growth in vitro, and were slightly below those required to inhibit the EGFR and ERBB receptors.

\section{Acknowledgments}

We acknowledge the clinical research assistant support of Helen Gallagher and Christopher Smith and the technical assistance of Inga Luckett and Radhika Thiruvenkatam.

\section{FUNDING}

This work was supported in part by NIH grant U01 CA81457 for the Pediatric Brain Tumor Consortium (JB), NCI grant R21 CA114937 (MF) and American Lebanese Syrian Associated Charities.

\section{REFERENCES}

1. Tang JY, Mackay-Wiggan JM, Aszterbaum M, Yauch RL, Lindgren J, Chang K, Coppola C, Chanana AM, Marji J, Bickers DR, Epstein EH Jr. Inhibiting the hedgehog pathway in patients with the basal-cell nevus syndrome. N Engl J Med. 2012; 366:2180-2188. [PubMed: 22670904]

2. Trunzer K, Pavlick AC, Schuchter L, Gonzalez R, McArthur GA, Hutson TE, Moschos SJ, Flaherty KT, Kim KB, Weber JS, Hersey P, Long GV, Lawrence D, Ott PA, Amaravadi RK, Lewis KD, Puzanov I, Lo RS, Koehler A, Kockx M, Spleiss O, Schell-Steven A, Gilbert HN, Cockey L, Bollag G, Lee RJ, Joe AK, Sosman JA, Ribas A. Pharmacodynamic Effects and Mechanisms of Resistance to Vemurafenib in Patients With Metastatic Melanoma. J Clin Oncol. 2013

3. Lee EQ, Puduvalli VK, Reid JM, Kuhn JG, Lamborn KR, Cloughesy TF, Chang SM, Drappatz J, Yung WK, Gilbert MR, Robins HI, Lieberman FS, Lassman AB, McGovern RM, Xu J, Desideri S, Ye X, Ames MM, Espinoza-Delgado I, Prados MD, Wen PY. Phase I study of vorinostat in combination with temozolomide in patients with high-grade gliomas: North American Brain Tumor Consortium Study 04-03. Clin Cancer Res. 2012; 18:6032-6039. [PubMed: 22923449]

4. Fouladi M, Park JR, Stewart CF, Gilbertson RJ, Schaiquevich P, Sun J, Reid JM, Ames MM, Speights R, Ingle AM, Zwiebel J, Blaney SM, Adamson PC. Pediatric phase I trial and pharmacokinetic study of vorinostat: a Children's Oncology Group phase I consortium report. J Clin Oncol. 2010; 28:3623-3629. [PubMed: 20606092]

5. Galanis E, Jaeckle KA, Maurer MJ, Reid JM, Ames MM, Hardwick JS, Reilly JF, Loboda A, Nebozhyn M, Fantin VR, Richon VM, Scheithauer B, Giannini C, Flynn PJ, Moore DF Jr, Zwiebel J, Buckner JC. Phase II trial of vorinostat in recurrent glioblastoma multiforme: a north central cancer treatment group study. J Clin Oncol. 2009; 27:2052-2058. [PubMed: 19307505]

6. Fouladi M, Stewart CF, Blaney SM, Onar-Thomas A, Schaiquevich P, Packer RJ, Gajjar A, Kun LE, Boyett JM, Gilbertson RJ. Phase I trial of lapatinib in children with refractory CNS malignancies: a Pediatric Brain Tumor Consortium study. J Clin Oncol. 2010; 28:4221-4227. [PubMed: 20713864]

7. Gajjar A, Hernan R, Kocak M, Fuller C, Lee Y, McKinnon PJ, Wallace D, Lau C, Chintagumpala M, Ashley DM, Kellie SJ, Kun L, Gilbertson RJ. Clinical, histopathologic, and molecular markers of prognosis: toward a new disease risk stratification system for medulloblastoma. J.Clin Oncol. 2004; 22:984-993. [PubMed: 14970185]

8. Ray A, Ho M, Ma J, Parkes RK, Mainprize TG, Ueda S, McLaughlin J, Bouffet E, Rutka JT, Hawkins CE. A clinicobiological model predicting survival in medulloblastoma. Clin Cancer Res. 2004; 10:7613-7620. [PubMed: 15569993] 
9. Gilbertson RJ, Bentley L, Hernan R, et al. ERBB receptor signaling promotes ependymoma cell proliferation and represents a potential novel therapeutic target for this disease. Clin.Cancer Res. 2002; 8:3054-3064. [PubMed: 12374672]

10. Gilbertson RJ, Hill DA, Hernan R, Junttila TT, Frank AJ, Haapasalo H, Connelly M, Wetmore C, Curran T, Elenius K, Ellison DW. ERBB1 is amplfied and overexpressed in high-grade diffusely infiltrative pediatric brain stem glioma. Clin.Cancer Res. 2003; 9:3620-3624. [PubMed: 14506149]

11. Bachelot T, Romieu G, Campone M, Dieras V, Cropet C, Dalenc F, Jimenez M, Le Rhun E, Pierga JY, Goncalves A, Leheurteur M, Domont J, Gutierrez M, Cure H, Ferrero JM, Labbe-Devilliers C. Lapatinib plus capecitabine in patients with previously untreated brain metastases from HER2positive metastatic breast cancer (LANDSCAPE): a single-group phase 2 study. Lancet Oncol. 2013; 14:64-71. [PubMed: 23122784]

12. Bai F, Freeman BB 3rd, Fraga CH, Fouladi M, Stewart CF. Determination of lapatinib (GW572016) in human plasma by liquid chromatography electrospray tandem mass spectrometry (LC-ESI-MS/MS). J Chromatogr B Analyt Technol Biomed Life Sci. 2006; 831:169-175.

13. Bredel M, Pollack IF, Hamilton RL, James CD. Epidermal growth factor receptor expression and gene amplification in high-grade non-brainstem gliomas of childhood. Clin Cancer Res. 1999; 5:1786-1792. [PubMed: 10430083]

14. Gilbertson RJ, Perry RH, Kelly PJ, Pearson AD, Lunec J. Prognostic significance of HER2 and HER4 coexpression in childhood medulloblastoma. Cancer Res. 1997; 57:3272-3280. [PubMed: 9242460]

15. Guo D, Prins RM, Dang J, Kuga D, Iwanami A, Soto H, Lin KY, Huang TT, Akhavan D, Hock MB, Zhu S, Kofman AA, Bensinger SJ, Yong WH, Vinters HV, Horvath S, Watson AD, Kuhn JG, Robins HI, Mehta MP, Wen PY, DeAngelis LM, Prados MD, Mellinghoff IK, Cloughesy TF, Mischel PS. EGFR signaling through an Akt-SREBP-1-dependent, rapamycin-resistant pathway sensitizes glioblastomas to antilipogenic therapy. Sci Signal. 2009; 2:ra82. [PubMed: 20009104]

16. Taskar KS, Rudraraju V, Mittapalli RK, Samala R, Thorsheim HR, Lockman J, Gril B, Hua E, Palmieri D, Polli JW, Castellino S, Rubin SD, Lockman PR, Steeg PS, Smith QR. Lapatinib distribution in HER2 overexpressing experimental brain metastases of breast cancer. Pharm Res. 2012; 29:770-781. [PubMed: 22011930]

17. Xia W, Mullin RJ, Keith BR, et al. Anti-tumor activity of GW572016: a dual tyrosine kinase inhibitor blocks EGF activation of EGFR/erbB2 and downstream Erk1/2 and AKT pathways. Oncogene. 2002; 21:6255-6263. [PubMed: 12214266]

18. Legault GH, Ballas M, Brown K, Vega E, Nusbaum A, Bloom M, Hochman T, Goldberg J, Golfinos J, Roland J, Allen J, Karajannis M. Phase II Trial of lapatinib in children and adults with neurofibromatosis type 2 and progressive vestibular schwannomas. Neuro-oncology. 2012; 14:i19. 
Table 1

Patients Characteristics of Eligible Patients $(n=8)$ in the Molecular Biology study

\begin{tabular}{|l|l|l|l|l|}
\hline & \multicolumn{2}{|c|}{ Stratum A } & \multicolumn{2}{c|}{ Stratum C } \\
\hline & & Number & & Number \\
\hline Characteristic & & & & \\
\hline Patients enrolled & & 4 & & 4 \\
\hline Eligible patients & & 4 & & 4 \\
\hline Male: female & & $3: 1$ & & $3: 1$ \\
\hline AGE (Years) & & & & \\
\hline Median & 8.8 & & 8.5 & \\
\hline Range & $3.1-20.1$ & & $5.8-11.2$ & \\
\hline & & Number & & Number \\
\hline Diagnosis & & & & \\
\hline Ependymoma, Anaplastic & & 0 & & 4 \\
\hline Medulloblastoma, NOS & & 4 & & 0 \\
\hline Prior therapy & & & & \\
\hline Radiotherapy only & & & & 1 \\
\hline Chemotherapy and radiotherapy & & 4 & & 3 \\
\hline Courses of lapatinib & & & & \\
\hline Median (range) & & $1.5(1-5)$ & & $4(1-6)$ \\
\hline
\end{tabular}




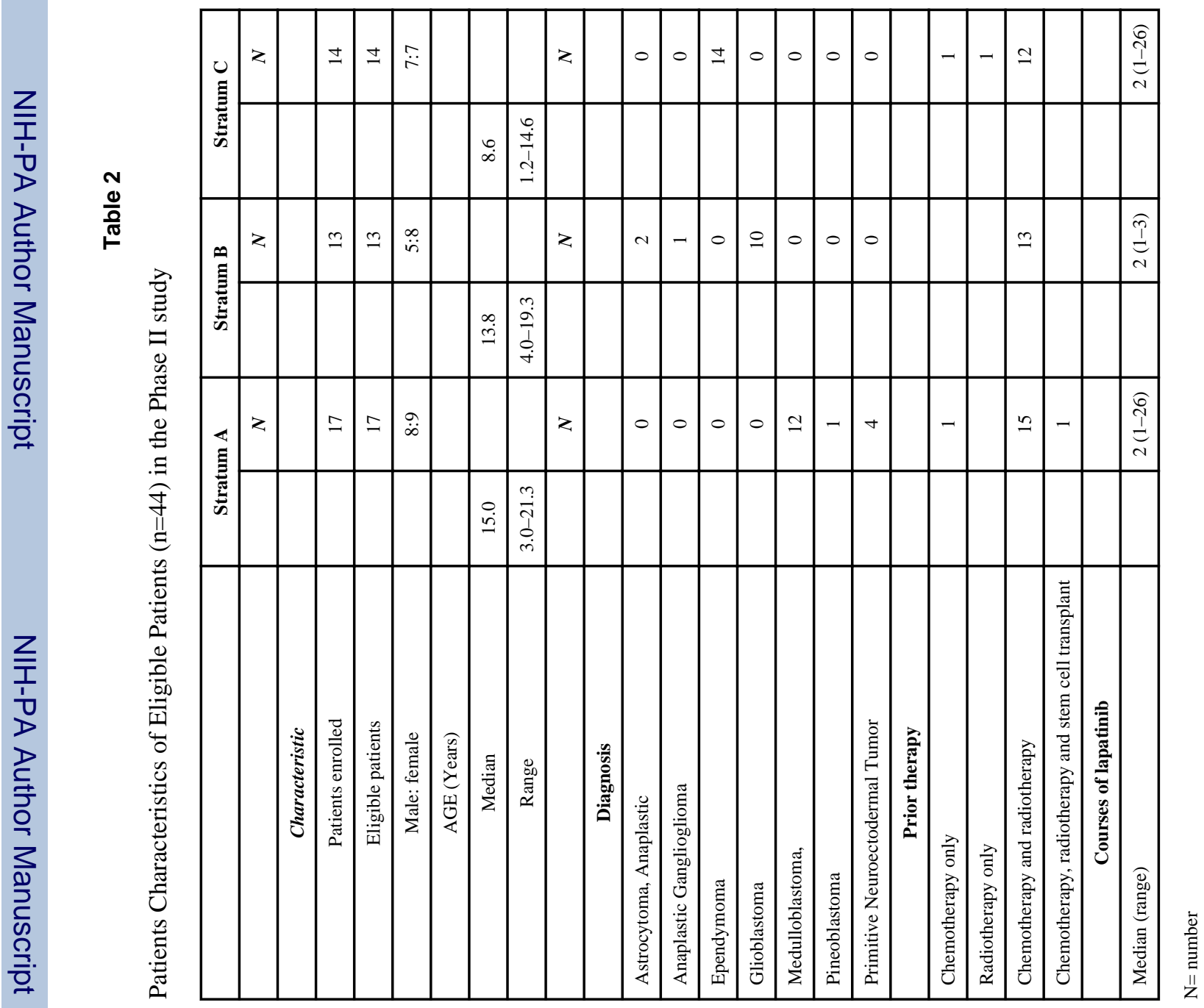

J Neurooncol. Author manuscript; available in PMC 2014 November 28. 


\section{Table 3}

Number of Adverse Events ( $\geq$ Grade 2) attributed to therapy in patients in each stratum in the Molecular Biology Phase

\begin{tabular}{|c|c|c|c|c|}
\hline \multirow{3}{*}{$\begin{array}{l}\text { Number of Episodes for Each Toxicity. (Within a patient, the highest grade is reported for each episode) } \\
\text { Toxicity }\end{array}$} & \multirow{2}{*}{\multicolumn{2}{|c|}{$\begin{array}{c}\text { Stratum A } \\
\text { Grade }\end{array}$}} & \multirow{2}{*}{\multicolumn{2}{|c|}{$\begin{array}{c}\text { Stratum C } \\
\text { Grade }\end{array}$}} \\
\hline & & & & \\
\hline & 2 & 3 & 2 & 3 \\
\hline Diarrhea & 1 & & & 2 \\
\hline Anorexia & 3 & & 2 & \\
\hline Vomiting & 1 & & 1 & 1 \\
\hline Fatigue & 1 & & & \\
\hline Rash/desquamation & 1 & & & \\
\hline dehydration & & & & 1 \\
\hline Pain (abdomen NOS) & 1 & & & \\
\hline Fever I in the absence of neutropenia & & & 1 & \\
\hline ALT, SGPT (serum glutamic pyruvic transaminase) & 1 & 1 & 1 & 1 \\
\hline hypokalemia & & 1 & & 2 \\
\hline hypophosphatemia & & 1 & & \\
\hline hyperbilirubinemia & & & & 1 \\
\hline AST, SGOT (serum glutamic oxaloacetic transaminase) & 1 & & & 1 \\
\hline Sodium, serum-low (hyponatremia) & & & & 1 \\
\hline Neutrophils/granulocytes (ANC/AGC) & 1 & & & . \\
\hline
\end{tabular}




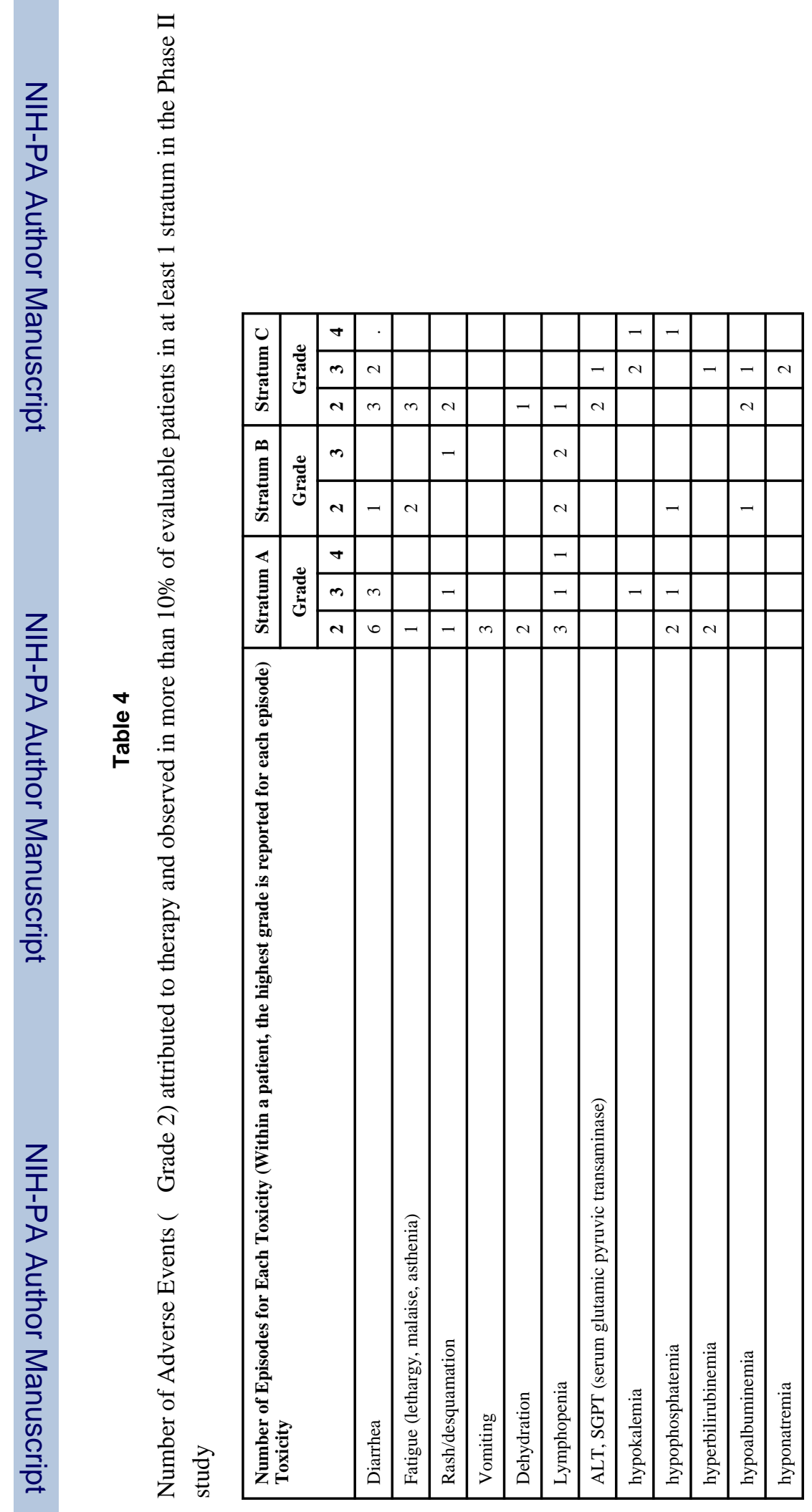

J Neurooncol. Author manuscript; available in PMC 2014 November 28. 